ORIGINAL ARTICLES

SPECIAL ISSUE

\title{
USER DESIGN METHODOLOGY THROUGH IDEA EVALUATION ANALYSIS SYSTEM
}

\section{- MOBILE PHONE DESIGN TARGETING KOREAN \& CHINESE USERS -}

\author{
Su-kyoung JEONG* and Jung-pyo HONG** \\ * Chonbuk National University, 664-14 Dukjin-Dong, Dukjin-Gu, Jeonju, Republic of Korea \\ ** Chonbuk National University, 664-14 Dukjin-Dong, Dukjin-Gu, Jeonju, Republic of Korea
}

\begin{abstract}
In a highly developed industrial society, the meaning of design is the core of corporate management strategies and furthermore, it is a major issue that determines the national competitiveness. It is also a means to acquiring a continuing competitive edge. In addition, there is a growing importance for design procedures according to the expansion of the design development field. The effective management of design procedures plays a crucial role of both reducing time and expenses, as well as for gaining a competitive edge. However, due to the variousness and complex designs of consumer classes and users, it is difficult to make an objective and feasible evaluation for measuring whether a completed design will be successful. In addition, it is not an easy task for designers to accurately identify the various demands of consumers based on the data provided in the marketing field. Therefore, designers require studies on the methods and techniques for properly identifying the consumer needs and applying them to design.

The objective of this study is to present a new design method to used a user evaluation analysis system. The design methods utilizing the user evaluation analysis system, a greater sense of satisfaction can be granted to users through the final design and it is expected to bring about procurement of market information to the company and designers, while also resulting in lowered expenses in the design development procedure. The aim of research is to get a actual design with the concept derived from consumer's preference between Korean and Chinese, but there is no meaning to get design concept of each nation that have same results with factors of preferences in experiments. Therefore, to make questionnaire in detail enable to clarify the characteristic of consumers and users use with mobile phone and apply to design process as results in further research.
\end{abstract}

Keywords: Design Methodology, Product Design, Design Evaluation \& Analysis

\section{INTRODUCTION}

Recently, the global management method of doing business throughout the world is at a trend of being generalized as companies are satisfying the unique and various demands of local customers by having the quality of global predominance in its competition. And within such global market environment and rapid change of product paradigm, design is setting its position as key element for controlling success or failure of the company.

The important thing in designing is to satisfy the user by understanding the change in sensitive needs of customers. Therefore, a company has to consider the objectives of product design expected in the future based on sensitive demands of user and apply them in deriving the product design and establishing the product development strategy of the company in the future through such consideration.

This study is to validate the possibility on initial objective of designing through user evaluation in the ideal conception process which is the initial stage of product development and to present the specific design approach method of giving higher value for users.

To make this possible, an idea evaluation analysis system has been developed to gather the evaluation data of users and use the gathered data that has been analyzed on a real time basis in the final outcome of the design.

The method of this research investigate on the online survey used in the idea evaluation analysis system and the aesthetic factors that are design evaluation factors while explaining the system outline, technological environment as well as the survey program and analysis program forming up the system. And it has been performed in the order of developing and experimenting the mobile phone design targeting Korean and Chinese users.

\section{CONSUMER EVALUATION OF THE DESIGN}

\subsection{Consumer Reaction on Product Design}

Once the product is developed, while consumers show various psychological reactions on this, the product evaluated in a positive way by consumers becomes the target of purchase and the product evaluated in a negative way by consumers run out of its life span by not being purchased again.

Therefore, the design is having an enormous influence on the decision to purchase by the consumer as an important variable making up the product and one factor of marketing strategy. [12]

Such improvement on the level of awareness followed by various changes of social culture and the change of product market environment are acting as changing factors 
of product purchase while the reality in which the preference and taste of product is also gradually being changed along with living standard of consumers has to be utilized as strategic factor in the development stage of new products. [1]

According to the study results of Young Soon Park (1985), the percentage of responding the concept of product design perceived by consumers as exterior, appearance and shape was the highest. The color was next highest and showed in the order of modern sense, atmosphere, practical functions and convenience. [13]

If this result is interpreted by characteristics of product design, exterior, appearance, shape and color, etc are design factors arousing aesthetic appreciation while the modern sense and atmosphere, etc can be related with symbolism as well as relating practical functions convenience, structure, and design, etc as functionality.

Although the product design requires various types of factors such as color, texture, material and function, etc other than the shape, the significance of shape has priority among them. Also, while the preference in the form of design is at the sense of stability, the shape must be in a stable form in order to become a factor of beauty because an unstable form also brings a sense of insecurity to the mind and one must appeal to shape the most to show the aesthetic strength and power. [6]

\subsection{Evaluation Method}

In present times when the difference of quality between companies is not being distinguished much, the consumer needs are being highlighted a great deal as a factor to induce discrimination with other companies. Therefore, the consumer needs are becoming a scale for measuring success or failure of product depending on how well they have been reflected on the product or how well the consumer needs have been guided to the product.

Because the purpose of product design is satisfying the needs of consumers to make their lives abundant, consumer needs has a close relationship as the purpose and method of product development. And consumer needs are not the ones limited to product design, but their importance is recognized in all areas related to product development and the study is being performed on the method of research for clarifying the concept of needs and understanding the needs especially in the field of marketing, consumer behavior research and in the field of consumer psychology in a broader sense.

While the consumer research can be classified into two types of qualitative method and quantitative method, the qualitative method has a limitation of not being able to measure the quantitative scale while being able to understand a little more specific details within a short period of time and the quantitative method can be utilized in a useful way through various analyses once the research is completed while requiring a lot of time and expenses.

I would say that it saves time and expenses because it is highly valuable for being used in the future projects. There is Questionnaire for a typical quantitative method and there are Town Watching, F.G.I (Focus Group Interview), Life Style Analysis, Scenario Analysis and Observation, etc for qualitative methods.

This study has developed and used the system as questionnaire method among the methods above.

\section{ONLINE SURVEY AND DESIGN EVALUATION FACTOR}

\subsection{Online Survey}

The survey which is a typical quantitative method is mostly used in understanding the realities of purchase and usage, reaction toward the product, STP analysis and understanding the market characteristics, understanding the awareness and attitude as well as understanding the advertisement effect and brand image.

The online research method is the one which is being widely used because it has an advantage of being able to secure many respondents promptly by escaping the restrictions in research time and place using the internet which is connected throughout the world. [2]

And while the internet survey has many advantages, it

Table 1: Consumer Survey Methods \& Characteristics

\begin{tabular}{|c|l|}
\hline Consumer Survey Methods & \multicolumn{1}{|c|}{ Characteristics } \\
\hline Questionnaire & $\begin{array}{l}\text { The method of having research candidates } \\
\text { to respond with the same method using } \\
\text { standardized questionnaire with set pattern }\end{array}$ \\
\hline Town Watching & $\begin{array}{l}\text { The method of reading out the atmosphere } \\
\text { and trend of the times after observing } \\
\text { images and symbols created by various } \\
\text { components }\end{array}$ \\
\hline FGI(Focus Group Interview) & $\begin{array}{l}\text { The method of discussing a topic prepared } \\
\text { for a certain specific purpose in a group of } \\
\text { few members (5-6 people) gathered for the } \\
\text { reason of that purpose }\end{array}$ \\
\hline Lifestyle Analysis & $\begin{array}{l}\text { The method to sub-categorize the market } \\
\text { according to the lifestyle of user by escap- } \\
\text { ing fromthedemographicsub-categorization } \\
\text { method of the past }\end{array}$ \\
\hline Observation & $\begin{array}{l}\text { The future prediction technique which can } \\
\text { be applied throughout the entire design } \\
\text { process from the idea conception of product } \\
\text { and capturing opportunity up to the user } \\
\text { atmosphere, technology and purpose of end } \\
\text { product by describing the lifestyle of } \\
\text { consumers and expected circumstances of } \\
\text { product atmosphere to understand the } \\
\text { potential needs by describing as scenario }\end{array}$ \\
\hline $\begin{array}{l}\text { The process of analyzing situations happen- } \\
\text { ing in the user environment targeting } \\
\text { consumers by an interpretation framework } \\
\text { which is appropriate for design develop- } \\
\text { ment purpose }\end{array}$ \\
\hline analys
\end{tabular}


Table 2: Comparing Characteristics of Survey Method

\begin{tabular}{|l|c|c|c|c|}
\hline \multicolumn{1}{|c|}{ Characteristic } & Mail & $\begin{array}{c}\text { Personal } \\
\text { Interview }\end{array}$ & Phone & Internet \\
\hline $\begin{array}{l}\text { Ability to handle } \\
\text { the complicated } \\
\text { survey }\end{array}$ & D & A & A & B \\
\hline $\begin{array}{l}\text { Ability to gather } \\
\text { mass quantity of } \\
\text { data }\end{array}$ & C & A & A & B \\
\hline $\begin{array}{l}\text { Accuracy of } \\
\text { sensitive } \\
\text { questions }\end{array}$ & B & B & B & B \\
\hline $\begin{array}{l}\text { Figures of } \\
\text { interview } \\
\text { influence }\end{array}$ & A & D & D & A \\
\hline $\begin{array}{l}\text { Degree of } \\
\text { sample control }\end{array}$ & C & C & C & C \\
\hline Required time & D & B & B & B \\
\hline $\begin{array}{l}\text { Expected } \\
\text { reaction ratio }\end{array}$ & C & C & C & C \\
\hline Expenses & B & C & C & C \\
\hline \multicolumn{4}{|l|}{ (A: Excellent, B: Good, C: Fair, D: Poor) } \\
\hline
\end{tabular}

can especially gather the mass quantity of data within a short period of time and the statistics processing of repossess is simple. Therefore, the reliability on investigated results of internet research would gradually become higher along with explosive increase of population and fast spread of internet users while it is expected to be used as a typical technique of the survey.

\subsection{Design Evaluation Factor}

In terms of designing, the content stands for the beauty possessed by the content itself for the beauty possessed by the style in the artwork as a formative factor of aesthetic dimension that is hard to be explained and the style is define as the beauty which the style appeals to the senses such as harmony, balance and rhythm as the dimension in which the users are able to easily identify the form.

If we look at the aesthetic research of Hong, Jung pyo (2003), the abstract aesthetic dimensions have been explained by dividing into content beauty and beauty of form as shown in the figure below. [5]

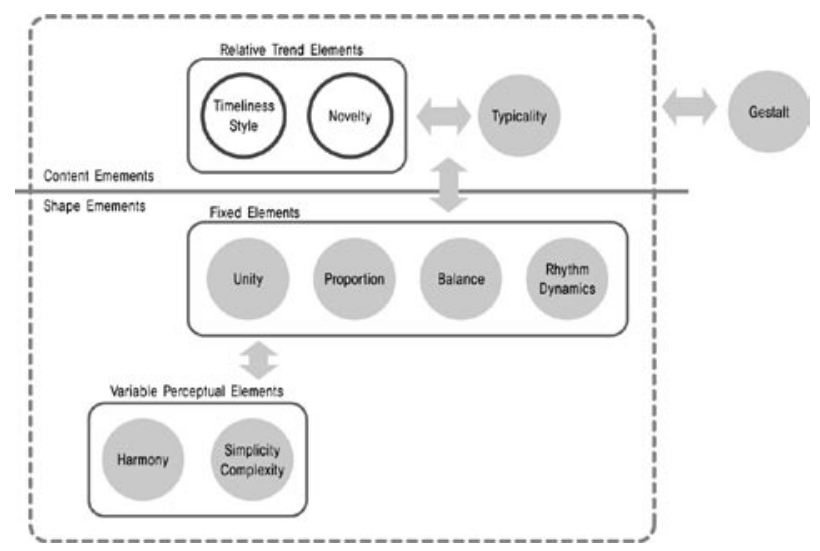

Figure 1: Relationship between Aesthetic Evaluation Factors
Because the standard of content beauty and beauty of form become different according to the individual standard value felt from aesthetic factors by an individual, it isn't possible to explain abstract aesthetic dimensions by completely dividing them into content beauty and beauty of form. But the validity has been acknowledged as the result of many experiments and this research has also classified into content beauty and beauty of form to be used as evaluation factors of ideal evaluation analysis system.

Table 3: Aesthetic Evaluation Factors of Design

\begin{tabular}{|c|c|c|}
\hline \multirow{6}{*}{$\begin{array}{l}\mathrm{C} \\
\mathrm{O} \\
\mathrm{N} \\
\mathrm{T} \\
\mathrm{E} \\
\mathrm{N} \\
\mathrm{T}\end{array}$} & Simplicity & $\begin{array}{l}\text { Degree of uneven arrangement, number of compo- } \\
\text { nents, degree of difference and degree of } \\
\text { gorgeousness }\end{array}$ \\
\hline & Balance & $\begin{array}{l}\text { Sense of equilibrium that can be influenced by shape } \\
\text { and relative position of the design }\end{array}$ \\
\hline & Rhythm & $\begin{array}{l}\text { Existence of sense of movement and sense of tension } \\
\text { in the stimulating design }\end{array}$ \\
\hline & Unity & Unity of design and overall integrity of factors \\
\hline & Proportion & $\begin{array}{l}\text { Ratio that can be gained by dividing one side into } \\
\text { two segments }\end{array}$ \\
\hline & Harmony & $\begin{array}{l}\text { Degree of how well all factors get along with each } \\
\text { other }\end{array}$ \\
\hline \multirow{3}{*}{$\begin{array}{l}\mathrm{F} \\
\mathrm{O} \\
\mathrm{R} \\
\mathrm{M}\end{array}$} & Timeless & Degree of the trend which is currently popular \\
\hline & Typicality & $\begin{array}{l}\text { Degree of representing the category which the } \\
\text { product belongs to }\end{array}$ \\
\hline & Novelty & New sensation \\
\hline
\end{tabular}

\section{IDEA EVALUATION ANALYSIS SYSTEM}

\subsection{System Outline and Technological Environment}

The idea evaluation analysis system provides a direct judgment data to designers through a prompt feedback on new idea proposal based on quantitative data shown in numeric values using the analysis program for the qualitative evaluation data of users with a survey program.

The language used in the system is PHP. and the version 1.0.5 has been used. It can be used by interlocking at Apache which is a web server and the Apache version is 2.2.6. For the database system, My-SQL which is a public database server has been used and the version 4.0 has been used.

\subsection{Online Survey Program}

The survey program has been developed in order to gain a qualitative evaluation data of user for the interior of the

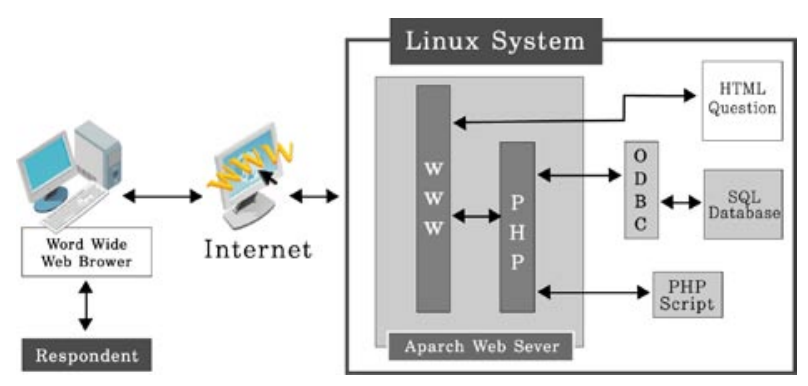

Figure 2: Flow Cart of Online Survey System 
design. The basic structure of program is based on the survey method which is a quantitative method that can be useful through various analyses of researched data as examined previously.

The details of survey are composed of the preference within design, importance of components and degree of preference, evaluation by aesthetic factors and demographic categories that are strategic factors of user subdivision. [9]

Table 4: Survey Categories and Methods

\begin{tabular}{|l|l|}
\hline \multicolumn{1}{|c|}{ Category } & \multicolumn{1}{c|}{ Method } \\
\hline Preference & - Evaluate the degree of preference using 7 point scale \\
\hline $\begin{array}{l}\text { Importance of } \\
\text { Components }\end{array}$ & $\begin{array}{l}\text { - Order of importance for the factors forming up the } \\
\text { design }\end{array}$ \\
\hline $\begin{array}{l}\text { Preference of } \\
\text { Components }\end{array}$ & $\begin{array}{l}\text { - Evaluate the degree of preference by components } \\
\text { using 7 point scale }\end{array}$ \\
\hline $\begin{array}{l}\text { Aesthetic } \\
\text { Evaluation }\end{array}$ & $\begin{array}{l}\text { - Evaluate the degree of nine aesthetic factors felt from } \\
\text { the stimulants using 7 point scale }\end{array}$ \\
\hline $\begin{array}{l}\text { Demographic } \\
\text { Details }\end{array}$ & $\begin{array}{l}\text { - Objective questions followed by categories of age, } \\
\text { gender, location, marital status, education, income and } \\
\text { occupation. }\end{array}$ \\
\hline
\end{tabular}

\subsection{Analysis Program}

The analysis program is made up of respondent status, analysis by survey categories and storage of excel data. The respondent status is divided into total number of respondents as well as age, gender, location, marital status, education, income and occupation that are demographic variables. The analysis by survey categories are able to identify the preference of design, preference and importance by components as well as the importance of aesthetic factors evaluated by users. Also, the data can be saved as excel file (design_report.xls) to be used in other analysis programs.

\section{DEVELOPMENT OF MOBILE PHONE DESIGN}

\subsection{Design Development Process}

The development of mobile phone design using ideal evaluation analysis system is performed as follows. First, after selecting the experiment target, the data of proposal which is most preferred by the user is analyzed using ideal evaluation system for the design proposal selected by going through the idea sketch. And using the analyzed data, the final design proposal is derived.

\subsection{Mobile Phone Market}

The domestic mobile phone industry has tremendous influence in our domestic economy and has set its position as a key item which has to be responsible for Korean economy for considerable period of time even in the future. [11]

Also in case of the Chinese mobile phone industry, it

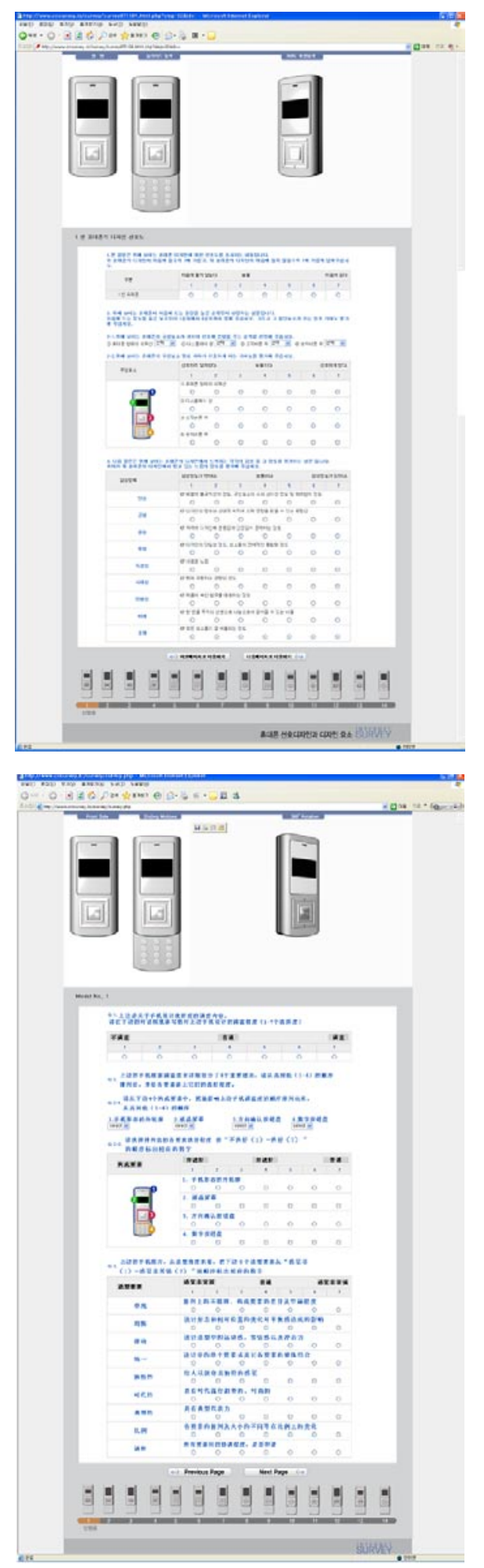

Figure 3: Online Survey Website

(Up : Korean User Under : Chinese User)

could be called the most typical industry in which the diversification and heightening throughout the whole industrial structure along with rapid technological growth since 2003. Seen from such trend, mobile phone companies in China are expected to accelerate their pursuit in the field of designing in which the companies of our country 

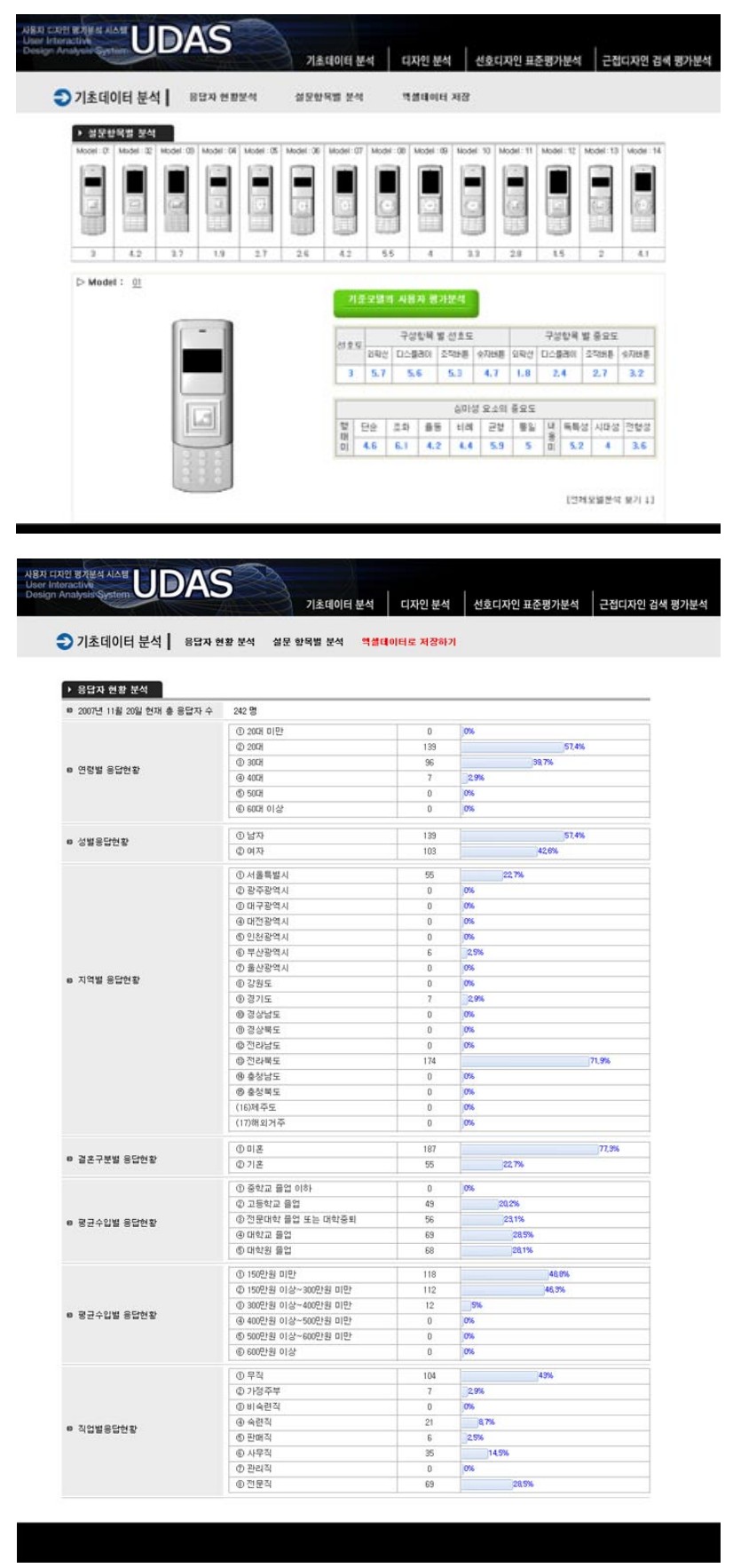

Figure 4: Analysis of Survey Results

\section{Deriving design idea proposal}

Identifying consumer preference and preference factors using idea evaluation system

Deriving design concept using analyzed datal

Deciding the final design proposal

Figure 5: Design Development Process have been predominant in their technological competitiveness in the past as the whole process from designing, manufacture, purchase, sale to distribution have been localized.

In order to occupy predominance in the global market, the most important thing is to identify the needs of customers. Therefore, it would be necessary to promptly apply in designing by understanding what factors the design evaluation is based on while the users actually make the purchase and what factors act as excellent factors to users.

\subsection{Deriving the Idea Proposal}

For the design idea proposal, five design factors of outer line, display, control key section and number key section forming up the shape of mobile phone based on slide type which is preferred the most by users among many mobile phone types.

And each factors can include the functional characteristics of the product and using the rectangle and circle excluding the model without negative sensation and characteristics among the visual evaluation sense that basic models have as default models [4], the idea proposal from these has been unfolded to derive the design proposal of final 14 types.

\subsection{System Utilization and Data Analysis}

For the 14 design proposals above, the following result data have been derived using idea evaluation analysis system based on responses from October 1st to 31st, 2007.

The total number of questionnaire respondents are 392 people (242 Korean people, 150 Chinese people) and mostly consisted of single men and women $(57.4 \%$ men,

Table 5: Visual Impression of Basis Shapes

\begin{tabular}{|c|c|c|c|c|}
\hline & Rectangle & Circle & Triangle & Polygon \\
\hline Shape & $\vdots$ & & \\
\hline $\begin{array}{c}\text { Visual } \\
\text { Impression }\end{array}$ & hard & soft & angular & anonymous \\
\hline
\end{tabular}
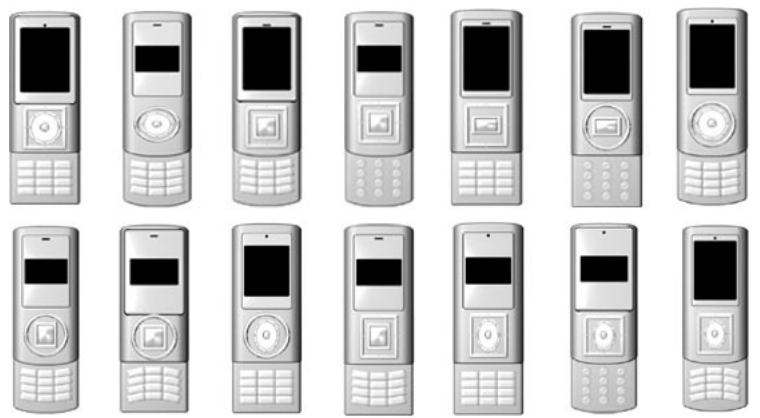

Figure 6: Design Idea draft 


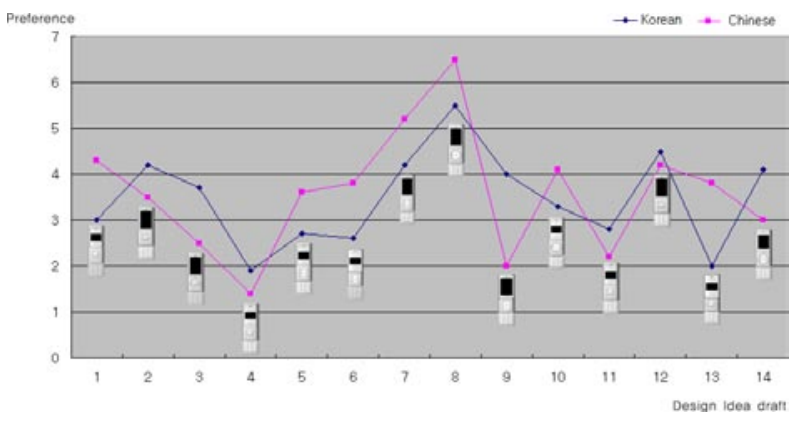

Figure 7: Design Idea preference

$42.6 \%$ women) with education background of high school or higher in the age group of twenties and thirties (95\%).

The results of cellular phone preference by respondents showed similar results between two countries like below.

The result of analyzing the degree of preference and preference factors of mobile phone evaluated by Korean and Chinese respondents were shown as below. The model which was preferred the most by respondents had the score of 5.5 and had the formative characteristics of round type outer line, large display window, fixed number of control key section and downward rectangular number key section

And for the order of importance in components, they had influence on degree of preference in the order of display section, number key, control key and outer line.

Among aesthetic factors of preferred design, the beauty of form has been identified as being important in the order of harmony (6), balance (5.6), rhythm and unity (5), proportion (4.8) and simplicity (4.6) while the content beauty has been identified as being important in the order of periodic trend (5), typicality (4.4) and uniqueness (4.5) so that the periodic trend is important factor.

\subsection{Final Design Proposal Using Analyzed Data}

Using the analyzed result like above as basic concept,

Table 6: Result of analyzing the degree of preference and preference factors

\begin{tabular}{|c|c|c|c|}
\hline \multicolumn{2}{|c|}{ Factors } & Korean & Chinese \\
\hline \multirow{4}{*}{$\begin{array}{c}\text { importance in } \\
\text { components }\end{array}$} & 1 & display & display \\
\cline { 2 - 4 } & 2 & number key & control key \\
\cline { 2 - 4 } & 3 & control key & number key \\
\hline \multirow{4}{*}{$\begin{array}{c}\text { aesthetic factors } \\
\text { of preferred } \\
\text { design }\end{array}$} & Simplicity & outer line & outer line \\
\cline { 2 - 4 } & Balance & 5.8 & 4.5 \\
\cline { 2 - 4 } & Rhythm & 5.3 & 5.5 \\
\cline { 2 - 4 } & Unity & 5.2 & 5 \\
\cline { 2 - 4 } & Proportion & 4.8 & 4.8 \\
\cline { 2 - 4 } & Timeless & 5.8 & 4.9 \\
\cline { 2 - 4 } & Typicality & 4.3 & 6.3 \\
\cline { 2 - 4 } & Novelty & 4.8 & 4.9 \\
\hline
\end{tabular}

the ideal sketch (proposal A, proposal B) has been developed.

Among the idea proposals above, the outcome of rendering by making proposal $\mathrm{B}$ as the final proposal is shown as below.

\section{CONCLUSION AND FURTHER WORK}

The parts that act as important purchase factors while the consumer searches information on the product or performs the action of purchase are diverse from visual and specific factors to psychological factors such as the formative factor making up the product, functional characteristics and convenience, quality and brand image.

The surrounding environment of designing is changing
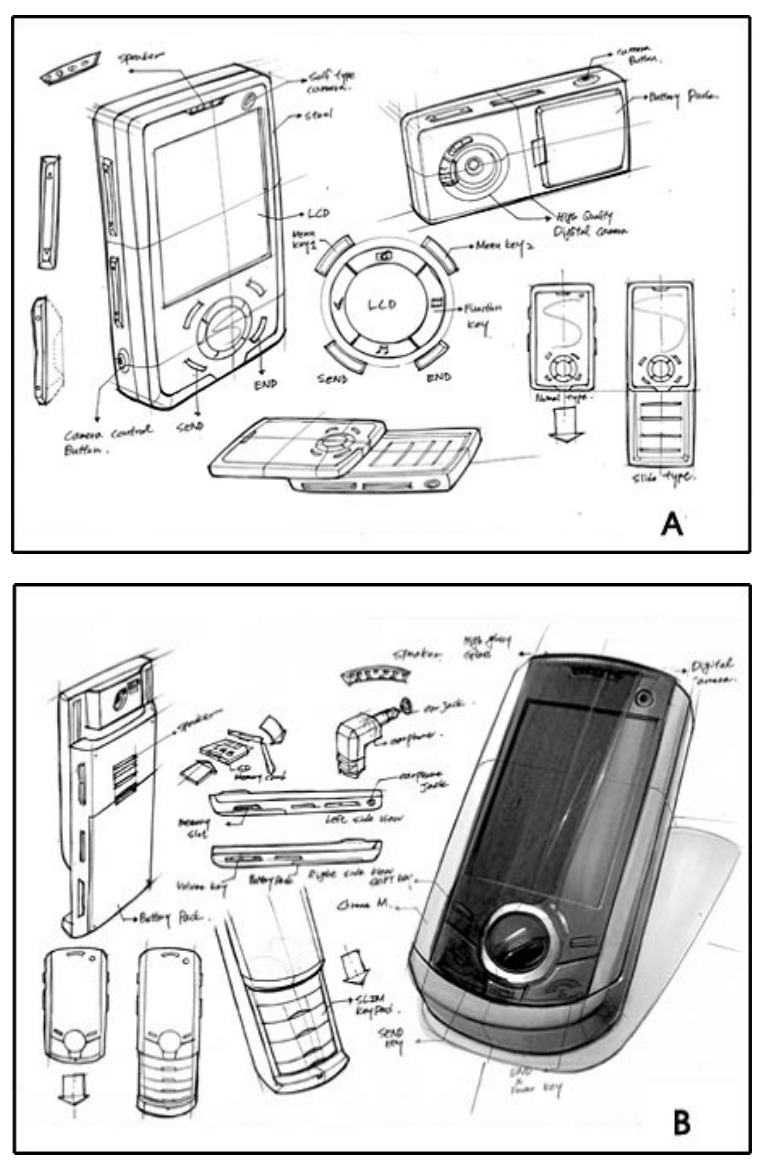

Figure 8: Idea Sketch

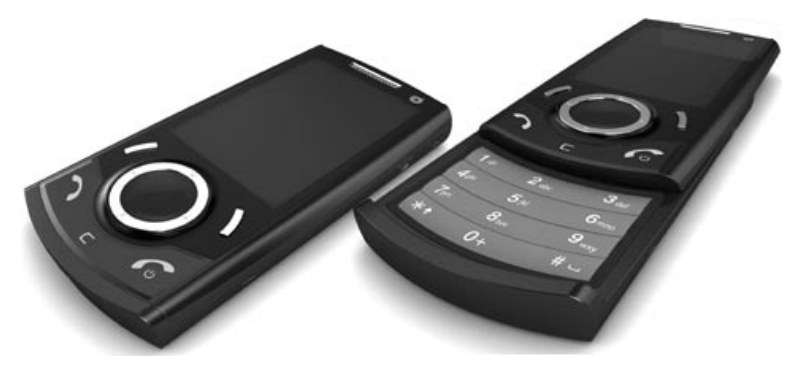

Figure 9: Final Design 
rapidly in many aspects such as various appetite increase of users and competition between the company and the nation while it is becoming difficult to cope with these circumstances using a design or product development method by monotonous and unchanged subjectivity of designers.

While the design is being set up based on consumer and user survey followed by age group or gender according to the targeted market set while developing the design, it is difficult to reflect the needs of users perfectly at the stage of developing the design.

Therefore, the designed outcome that has reflected the design by analyzing and identifying from the idea conception which is the initial stage of designing for the needs of users would be able to raise the success rate of the product and gain predominance in the market of fierce competition.

Also, the designing method using idea evaluation analysis system is a useful tool that can identify various needs of users and cope flexibly with the rapidly changing market trend so that its value can be expected.

The summary of limitations and future research in this study are as follows.

First, the designing method using the system validated by experiment must be validated by applying in the actual designing field. And by researching the evaluation category to specifically identify the needs of users, it must be applied to the survey program.

The aim of research is to get a actual design with the concept derived from consumer's preference between Korean and Chinese, but there is no meaning to get design concept of each nation that have same results with factors of preferences in experiments.

Therefore, to make questionnaire in detail enable to clarify the characteristic of consumers and users use with mobile phone and apply to design process as results in further research.

\section{REFERENCES}

1. Mary Jo. Bitner; Servicescapes: The impact of Physical Surroundings on Customers and Employees, Journal of Marketing, pp.57-71 (1992).

2. Brian Dumaine; "Design That Sells and Sells and ..." Fortune, March 11, pp.94-96 (1991).

3. G.H.Lee; Internet Survey, Nanam, pp.59-72 (2000).

4. G.H.Park; Formative Arts, Gimundang, pp.136-138 (1998).

5. J.P.Hong; User's Aesthetic Response to Direct, Mediating and Interactive Effects of Content Aesthetic and
Form Aesthetics in Product Design, Chiba University, p.67 (2003).

6. J.S.Park; Jo-sun \& Art, Bumwoo, p.28 (1997).

7. Ellis, Seth Robert; A Psychometric Investigation of a Scale for Evaluation of the Aesthetic Element in Consumer Durable Goods, Unpublished Dissertation University of Aritana, pp.30-38 (1993).

8. S.K.Jeong; A study on the aesthetic analysis of product design, Chonbuk National University, pp.16-18 (2004).

9. S.K.Jeong; Design Methodology through UserFriendly Configuration Concept Evaluation Analysis, Chonbuk National University, pp.120-122 (2008).

10. S.K.Jeong, J.P.Hong; A Study on the aesthetic factors of product design according to user's preference, Korean Journal of the science of Emotion \& sensibility; 8(3), pp.203-212 (2005).

11. S.Y.Hong; Korea economy report, Booktopia, (2003).

12. Wind, Jerry and Uijay Mahajan; Issues and Opportunities in New Product Development, Journal of Marketing Research, 34 (Feb.), pp.1-12 (1997).

13. Y.S.Park; The Development of Design Evaluation Instrument Using Semantic Differential Scales, Yonsei University, p.75 (1985).

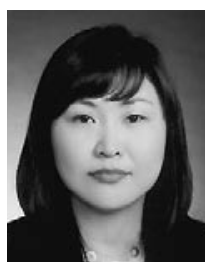

JEONG, Su-Kyoung

Su-Kyoung JEONG is adjunct professor at the department of industrial design in Korea Polytechnic Colleges, Korea. She taken the doctor's degree in Engineering. She is also a regular member of Korean Society of Design Science (KSDS), Korean Society for Emotion \& Sensibility (KSES), and Korean Society of Basic Design \& Art (KSBA). She teaches design methodology, product design, design Marketing and presentation skill in Chonbuk National University and Korea Polytechnic Colleges. She research interests include aesthetic design, design automation, and product design.

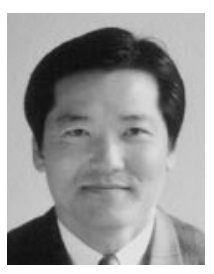

HONG, Jung-Pyo

Jung-Pyo Hong is professor of the department of Industrial design at Chonbuk National University, Korea. He is also director of Aesthetic Design Lab. Major areas of research interests include aesthetic Design, design methodology, and design creativity. $\mathrm{He}$ has a doctoral degree in Chiba University, JAPAN, and he consecutively filled executive director of Design research lab, LG Electronics Inc. Also, he takes active in consultation of LG electronic design part and invited designer in Korea design awards, the jury of Korea design awards, director of Korea society for Emotion \& Sensibility. 